This item was submitted to Loughborough's Research Repository by the author.

Items in Figshare are protected by copyright, with all rights reserved, unless otherwise indicated.

\title{
The effect of annealing pressure and time on the crystallinity of CZTSe
}

\section{PLEASE CITE THE PUBLISHED VERSION}

https://doi.org/10.1142/S0218625X18501512

\section{PUBLISHER}

(C) World Scientific Publishing

\section{VERSION}

AM (Accepted Manuscript)

\section{PUBLISHER STATEMENT}

This work is made available according to the conditions of the Creative Commons Attribution-NonCommercialNoDerivatives 4.0 International (CC BY-NC-ND 4.0) licence. Full details of this licence are available at: https://creativecommons.org/licenses/by-nc-nd/4.0/

\section{LICENCE}

CC BY-NC-ND 4.0

\section{REPOSITORY RECORD}

Katirci, Ramazan, and Michael Walls. 2019. "The Effect of Annealing Pressure and Time on the Crystallinity of Cztse". figshare. https://hdl.handle.net/2134/32093. 


\title{
The effect of annealing pressure and time on the crystallinity of CZTSe
}

\author{
Ramazan Katırc1*a,
}

E-mail: ramazan@asrelektrokimya.com; ramazankatirci@aydin.edu.tr

John Michael Walls ${ }^{\mathrm{b}}$,

E-mail: j.m.walls@lboro.ac.uk.

${ }^{a}$ Istanbul Aydın University, Beşyol Mah.Inönü Cad.No: 38, Sefaköy-Küçükçekmece / İstanbul/Turkey

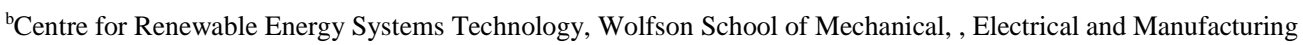

Engineering, Loughborough University, Leicestershire, LE11 3TU, U.K.

\begin{abstract}
In this study, the effect of annealing pressure and time on the homogeneity and the formation of the CZTSe structure was investigated. The deposition of the CZTSe coating was carried out using an electroplating method. The morphology and crystal structure of the coating was investigated using SEM-EDS, XRD and Raman spectroscopy. CZTSe films with optimised crystallinity and uniformity were obtained using an annealing process performed at 10 Torr for 1 hour. The use of lower pressures increases the crystallinity and the purity of the CZTSe film and decreases the density of secondary phases and the annealing time providing an additional benefit.
\end{abstract}

Keywords: Kesterite $\left(\mathrm{Cu}_{2} \mathrm{ZnSnSe} 4\right)$ electroplating; Photovoltaic Absorber; Thin film electrodeposition.

*Corresponding author: ramazan@asrelektrokimya.com; Phone: +905353313748; Fax: +902122767966

Permanent address: Talatpasa Mah. Celebi Cad. Yanihan Sk: No:5; Okmeydani-Kagithane/Istanbul-TURKEY 


\section{Introduction}

Solar radiation is the cleanest and most abundant energy sources on earth ${ }^{1}$ and can be converted into electrical energy by means of photovoltaic cells ${ }^{2-4}$. Thin film photovoltaic devices consist of $\mathrm{p}$ and n-type layers ${ }^{2}$. CdTe, CIGS and CIS thin film absorbers are commonly used as the p-type layer ${ }^{5}$. These materials contain toxic (Cd) or rare elements such as $\mathrm{In}$, and $\mathrm{Ga}^{6}$. As a result, research is being carried out to develop solar cells, which use an alternative non-toxic and abundant materials.

The Kesterite $\mathrm{Cu}_{2} \mathrm{ZnSnSe}_{4}$ (CZTSe) is a promising absorber material for photovoltaic modules, which contains earth abundant and non-toxic elements ${ }^{7}$. Thus, it has received much interest and many studies using this material have been reported. Many deposition methods have been used to deposit CZTSe thin films ${ }^{8-12}$. Electroplating is an attractive method since it is atmospheric and the low cost ${ }^{1,13}$ It can be used to deposit as single layers and multilayers ${ }^{14-15}$.

The CZTSe microstructure forms during an annealing process. The CZT (CuZnSn) layer, prior to annealing, consists of $\mathrm{Sn}, \mathrm{Cu}$ and $\mathrm{Sn}$ precursors together with $\mathrm{Cu}_{6} \mathrm{Sn}_{5}$, $\mathrm{CuZn}$ and $\mathrm{Cu}_{5} \mathrm{Zn}_{8}$ alloys ${ }^{2,16}$. The annealing process is carried out using a nitrogen or argon atmosphere at a specified temperature and pressure. CZT and Se ingots are placed in a graphite sample holder and Se evaporates during annealing ${ }^{9,17-19}$. Zhang et al. compared the annealing process performed by the RTA (Rapid Thermal Annealing) and CFA (Conventional Furnace Annealing). The results indicated that the RTA process facilitates the formation of single phase CZTSe absorbers with large grains. The band gap energy of the film is $0.98 \mathrm{eV}$ and the optical absorption coefficient is in the order of $10^{4} \mathrm{~cm}^{-1}$ in the visible region. The efficiency of CZTSe solar cells is $4.5 \%$. This study shows that a low-cost, non-vacuum process using co- 
electrodeposition with the subsequent RTA process is a promising method for the fabrication of CZTSe based solar cells ${ }^{20}$. Sundara et al. prepared the CZTS thin films by the four-source co-evaporation technique. They investigated the effect of the substrate at different temperatures $(523,573,623$ and $673 \mathrm{~K})$ and annealed it at 723 K. They found that the optimum substrate temperature to obtain single phase CZTSe films is $623 \mathrm{~K}^{21}$. The annealing process plays a crucial role in the formation of CZTS crystal structure. Some scientists studied the annealing atmosphere, including $\mathrm{H}_{2} \mathrm{~S}$ and $\mathrm{N}_{2}$ gas $^{5,6}$. But few studies has been reported investigating the effect of the annealing temperature and pressure together on the CZTSe crystal structure and uniformity ${ }^{22-23}$. In this study, the effect of annealing temperature and pressure on the CZTSe crystal structure and homogeneity has been investigated by using systematic method.

\section{Experimental}

$\mathrm{Cu}, \mathrm{Sn}$ and Zn (CZT) multilayer electroplating were carried out using a Thurlby 30V1A-model DC generator. The morphology and structure of the annealed films were investigated using XRD, Raman spectroscopy, and SEM-EDS. A Bruker D2 phaser model was used for XRD measurements, scanning 30 and $70^{\circ}$. The step was set to 0.02 with 2 steps per second. Raman spectroscopy measurements (LabRam HR model) were performed using the $633 \mathrm{~nm}$ line of a HeNe laser as an excitation source. Scanning Electron Microscopy was carried out on a JEOL JSM-7800F Highresolution analytical, Field Emission Scanning Electron Microscope (FE-SEM). Energy dispersive X-ray spectroscopy (EDS) microanalysis was obtained using an Oxford Instruments X-max $80 \mathrm{~mm}^{2}$ detector, combined with Aztec software allowing standardless quantitative elemental analysis to be carried out. 
Molybedum-coated soda-lime glass was used as the substrate. Prior to electrodeposition, the sample surfaces were cleaned using $6 \mathrm{~A} / \mathrm{dm}^{2}$ cathodic current for 5 minutes. $\mathrm{Cu}, \mathrm{Zn}$ and $\mathrm{Sn}$ were electrodeposited sequentially on the substrates (size $5 \times 5 \mathrm{~cm}^{2}$ ). The chemical contents of these baths are shown in Table 1 .

\section{Table 1.}

Varying pressures and times were used during the annealing process following electrodeposition. The experimental parameters are presented in Table 2. The samples were annealed using a nitrogen atmosphere at $540{ }^{\circ} \mathrm{C}$ in a graphite sample holder containing 0.6 Se ingots in a quartz tube.

\section{Table 2.}

\section{Results and discussion}

The annealing pressure and time are important parameters to obtain pure and homogeneous crystals of CZTSe. Thus, the optimum annealing conditions were investigated by varying the pressure and time of heat treatment. Six different annealing conditions were studied. The samples were named as in Table 2. In order to characterise the CZTSe crystals of these samples, XRD and Raman scattering measurements were evaluated together, because the peaks of $\mathrm{ZnSe}$ and $\mathrm{Cu}_{2} \mathrm{SnSe}_{3}$ secondary phases in XRD patterns are very similar to CZTSe and are difficult to distinguish ${ }^{5}$.

The peaks at 171, 193 and $233 \mathrm{~cm}^{-1}$ in the Raman spectra confirm the formation of CZTSe and the intensity of peaks indicate the crystal quality ${ }^{29}$. Fig. 1 shows the 3 points on the CZTSe deposition taken the Raman measurements and the results are presented in Fig. 2 (a-f). The current distribution on the substrate surface in the 
electroplating process is not uniform. Thus, the CZTSe thickness and the alloy ratio across the samples are different. This causes a drop in the quality and homogeneity of the CZTSe crystal during annealing ${ }^{27,29}$. S1 in Table 2 had the density and uniformity of CZTSe crystal structure and secondary phase was not observed (Fig. 2a). When the annealing time was raised to 2 hours, the density of CZTSe structure increased slightly, but the homogeneity was not altered (Fig. 2b). In region 1 of S3, the density of CZTSe was very high, but the density in the other regions reduced drastically. The homogeneity of the surface was too low (Fig. 2c). ZnSe secondary phases were also observed in the same region. When the annealing time in S4 was raised to 2 hours, the homogeneity of the CZTSe crystal structure grew significantly and the secondary phase was not detected (Fig. 2d). S5 and S6 (Fig. 2e-f) were annealed using 300 Torr pressure for 1 and 2 hours respectively. Although the CZTSe structure was observed in S5, the density of the CZTSe was too low. In addition, the density of the ZnSe secondary phase was too high. In order to confirm the CZTSe peak at $193 \mathrm{~cm}^{-1}$ in the Raman spectrum, an XRD measurement was carried out on the S5. Even though the peaks corresponding to CZTSe in the XRD spectrum were observed, the number of secondary phases and intensity were too high (Fig. 3). In S6 (Fig. 2f), when the annealing time was increased to 2 hours, the intensity of the CZTSe peak became distinct. But its density was still too low and CuSe secondary phase was observed. The surface homogeneity of samples improved when the annealing time increased.

\section{Fig. 1.}

Fig. 2.

Fig. 3. 
As is commonly known, the evaporation rate of materials is directly affected by the gas pressure. As the gas pressure decreases, the evaporation rate rises. Se has the lowest evaporation temperature among the elements in the CZTSe structure. Therefore, it is expected that the consumption of Se will be faster than the other elements during the annealing process. Fig. 4 shows the effect of changing the annealing pressure and time on the consumption of Se. The concentration of Se was $51.8 \%, 51.3 \%$, and $50.4 \%$, respectively, when the annealing pressure increased from 10 to 300 Torr and the annealing time was 1 hour. When the annealing time was increased to 2 hours, the concentration of Se decreased to $49.1 \%$, $51.0 \%$, and $51.0 \%$ respectively. The largest decrease in the Se quantity occurred when the gas pressure was 10 Torr and the annealing time was 2 hours. However, this decrease is not significant for the formation of CZTSe.

Fig. 4.

The effect of the annealing process on the morphology of the CZTSe coating is presented in Fig. 5. S1, S2 and S4 (Fig. 5 (a, b, d)) have a more uniform and compact morphology and the sizes of grain are smaller. In S3, S5 and S6 (Fig. 5 (c, e, f)), the sizes of the grains are not homogeneous and agglomeration has taken place. This may result from the secondary phases such as ZnSe, CuSe, etc. SEM micrographs and Raman scattering measurements revealed that the purest and the most homogeneous CZTSe crystal structure was obtained with the annealing conditions of S1.

Fig. 5.

The surface morphology of S1 is presented in Fig. 6. It reveals that the CZTSe coating has a compact and non-porous structure with triangular grains, whose size is generally between 0.5 and $1 \mu \mathrm{m}$. 
Fig. 6.

Fig. 7 shows the deterioration of the CZTSe coating surface. It is believed that the defects formed on the coating are due to hydrogen gas evolution trapped in the coating during electrodeposition, which creates internal pressure and results in cracks in the coating. It is known that when the electrodeposition process is carried out in water-based solutions, hydrogen gas evolves at the cathode due to water hydrolysis. If the evolved hydrogen gas does not leave the surface quickly, it may be trapped in the coating ${ }^{26}$.

\section{Fig. 7.}

Fig. 8 shows the XRD peaks from S1. The peaks corresponding to the crystal structure of CZTSe are observed in the XRD spectrum. Also, the peak corresponding to $\mathrm{MoSe}_{2}$ is present due to the reaction between Mo and Se elements. The intensity of this peak is weak. It has been reported that $\mathrm{MoSe}_{2}$ increase the adhesion strength between substrate and coating ${ }^{27}$. XRD peaks confirm the Raman measurements.

\section{Fig 8.}

\section{Conclusions}

In this study, the effects of annealing pressure and time on the formation and the homogeneity of the CZTSe structure were investigated. The results obtained from this study are summarized as follows:

The concentration and homogeneity of CZTSe decreased when the annealing pressure was raised. In addition, the number and density of secondary phases increased. 
$>$ The purest and most homogeneous crystallinity of CZTSe was obtained when the annealing pressure was held at 10 Torr for 1 hour.

$>$ The annealing process performed at low pressure enhanced the quality and homogeneity of the CZTSe structure and decreased the annealing time required significantly.

$>$ When the annealing pressure was raised from 10 to 100 Torr, the uniformity of the CZTSe deteriorated. However, when the annealing time was extended, the uniformity improved.

$>$ The decrease in the concentration of Se in the coating was negligible at the low annealing pressure.

$>$ The Mo-coated substrate deteriorated (Fig. 9b) when the pressure was raised to 300 Torr. However, when the annealing pressure was decreased to 10 Torr, the Mo- coated substrate did not deteriorate at $540{ }^{\circ} \mathrm{C}$ (Fig. 9a). The low annealing pressure prevents the deterioration of the Mo-coated substrate.

Consequently, the results show that it is possible to obtain the most uniform and purest CZTSe structure using a low annealing pressure and time.

Fig. 9.

In addition, hydrogen gas evolution due to water hydrolysis causes some defects on the surface because hydrogen gas is trapped in the coating. In order to prevent these defects, surfactants can be used to decrease the surface tension, which facilitates the release of hydrogen from the surface.

\section{Acknowledgement}

I acknowledge the support of The Scientific and Technological Research Council of Turkey (TUBİTAK) (Fellowship). I also would like to thank the Centre for 
Renewable Energy Systems Technology, Loughborough University, for their help

with substrate preparations, electrodeposition, and device fabrication.

\section{References}

1. $\quad$ S.M. Pawar, B.S. Pawar, a. V. Moholkar, D.S. Choi, J.H. Yun, J.H. Moon, et al., Single step electrosynthesis of $\mathrm{Cu}_{2} \mathrm{ZnSnS}_{4}$ (CZTS) thin films for solar cell application, Electrochim. Acta. 55 (2010) 4057-4061.

2. H. Flammersberger, Experimental study of $\mathrm{Cu}_{2} \mathrm{ZnSnS}_{4}$ thin films for solar cells, Uppsala Universitet, (2010) 117.

3. Q. Cao, O. Gunawan, M. Copel, K.B. Reuter, S.J. Chey, V.R. Deline, et al., Defects in Cu (In, $\mathrm{Ga}) \mathrm{Se}_{2}$ chalcopyrite semiconductors: A comparative study of material properties, defect states, and photovoltaic performance, Adv. Energy Mater. 1 (2011) 845-853.

4. A. Wesley Jeevadason, K. Kalidasa Murugavel, M.A. Neelakantan, Review on Schiff bases and their metal complexes as organic photovoltaic materials, Renew. Sustain. Energy Rev. 36 (2014) 220-227.

5. W. Septina, S. Ikeda, A. Kyoraiseki, T. Harada, M. Matsumura, Single-step electrodeposition of a microcrystalline $\mathrm{Cu}_{2} \mathrm{ZnSnSe}_{4}$ thin film with a kesterite structure, Electrochim. Acta. 88 (2013) 436-442.

6. S. Ahmed, K.B. Reuter, O. Gunawan, L. Guo, L.T. Romankiw, H. Deligianni, A High Efficiency Electrodeposited $\mathrm{Cu}_{2} \mathrm{ZnSnS}_{4}$ Solar Cell, Adv. Energy Mater. 2 (2012) 253-259.

7 Y.J. Kim, E.J. Jo, A.S. Kamble, M.G. Gang, J.H. Kim, J.H. Moon, J.H. Kim, Improving the solar cell performance of electrodeposited Cu2ZnSn (S, Se) 4 by varying the $\mathrm{Cu} /(\mathrm{Zn}+\mathrm{Sn})$ ratio, Sol. Energy. 145 (2017) 13-19.

8. F. Liu, Y. Li, K. Zhang, B. Wang, C. Yan, Y. Lai, In situ growth of $\mathrm{Cu}_{2} \mathrm{ZnSnS}_{4}$ thin films by reactive magnetron co-sputtering, Solar Energy Materials \& Solar Cells. 94 (2010) 2431-2434.

9. $\quad$ B. Ananthoju, F.J. Sonia, A. Kushwaha, D. Bahadur, N. V. Medhekar, M. Aslam, Improved structural and optical properties of $\mathrm{Cu}_{2} \mathrm{ZnSnS}_{4}$ thin films via optimized potential in single bath electrodeposition, Electrochim. Acta. 137 (2014) 154-163.

10. Y.B. Kishore Kumar, G. Suresh Babu, P. Uday Bhaskar, V. Sundara Raja, Preparation and characterization of spray-deposited $\mathrm{Cu}_{2} \mathrm{ZnSnS}_{4}$ thin films, Sol. Energy Mater. Sol. Cells. 93 (2009) 1230-1237.

11 A. Tang, Z. Li, F. Wang, M. Dou, Y. Pan, J. Guan, One step electrodeposition of Cu2ZnSnS4 thin films in a novel bath with sulfurization free annealing, Appl. Surf. Sci. 402 (2017) 70-77. doi:10.1016/j.apsusc.2017.01.079.

12 X. Guo, J. Han, H. Zhang, X. Lv, J. Yan, R. Sun, Sol-gel synthesis of Cu2ZnSnS4 thin films under mild conditions, J. Alloys Compd. 697 (2017) 361-366. 
13. K.V. Gurav, Y.K. Kim, S.W. Shin, M.P. Suryawanshi, N.L. Tarwal, U.V. Ghorpade, Pulsed electrodeposition of $\mathrm{Cu}_{2} \mathrm{ZnSnS}_{4}$ thin films: Effect of pulse potentials, Appl. Surf. Sci. 334 (2015) 192-196.

14. S. Delbos, Kësterite thin films for photovoltaics: a review, EPJ Photovoltaics. 3 (2012) 35004.

15. C.P. Chan, H. Lam, C. Surya, Preparation of Cu2ZnSnS4 films by electrodeposition using ionic liquids, Sol. Energy Mater. Sol. Cells. 94 (2010) 207-211.

16 B. Unveroglu, G. Zangari, Effect of cell configuration on the compositional homogeneity of electrodeposited $\mathrm{Cu}-\mathrm{Zn}-\mathrm{Sn}$ alloys and phase purity of the resulting $\mathrm{Cu}_{2} \mathrm{ZnSnS}_{4 \mathrm{v}}$ absorber layers, Electrochim. Acta. 255 (2017) 347-357.

17. P.J. Dale, K. Hoenes, J.J. Scragg, S. Siebentritt, A review of the challenges facing kesterite based thin film solar cells, 2009 34th IEEE Photovolt. Spec. Conf. (2009) 002080-002085.

18. A. Fairbrother, X. Fontané, V. Izquierdo-Roca, M. Placidi, D. Sylla, M. Espindola-Rodriguez, et al., Secondary phase formation in $\mathrm{Zn}$-rich $\mathrm{Cu}_{2} \mathrm{ZnSnSe}_{4}$ - based solar cells annealed in low pressure and temperature conditions, Prog. Photovolt Res. Appl. 15 (2007) 659-676.

19. L. Guo1, O.G. Yu Zhu, T. Gokmen, V.R. Deline, S. Ahmed, L.T. Romankiw, Electrodeposited $\mathrm{Cu}_{2} \mathrm{ZnSnSe}$ thin film solar cell with 7\% power conversion efficiency, Prog. Photovolt Res. Appl. 15 (2007) 659-676.

20. Y. Zhang, C. Liao, K. Zong, H. Wang, J. Liu, T. Jiang, et al., $\mathrm{Cu}_{2} \mathrm{ZnSnSe}_{4}$ thin film solar cells prepared by rapid thermal annealing of co-electroplated Cu-Zn-Sn precursors, Sol. Energy. 94 (2013) 1-7.

21. G. Suresh Babu, Y.B. Kishore Kumar, P. Uday Bhaskar, S. Raja Vanjari, Growth and characterization of co-evaporated $\mathrm{Cu}_{2} \mathrm{ZnSnSe}_{4}$ thin films for photovoltaic applications, J. Phys. D. Appl. Phys. 41 (2008) 205305.

22. I. Montoya De Los Santos, M. Courel, N.R. Mathews, X. Mathew, Study on the effect of annealing under pressure on the material properties of $\mathrm{Cu}_{2} \mathrm{ZnSn}(\mathrm{S}, \mathrm{Se})_{4}$ thin films, Mater. Sci. Semicond. Process. 68 (2017) 68-75.

23 W. Feng, J. Han, J. Ge, X. Peng, Y. Liu, Y. Jian, L. Yuan, X. Xiong, L. Cha, C. Liao, Influence of Annealing Temperature on CZTS Thin Film Surface Properties, J. Electron. Mater. 46 (2017) 288-295.

24. Allen J. Bard, Larry R. Falkner, Electrochemical Methods Fundamentals and Applications, John Willey and Sons, (1980) 2001.

25. M. Schlesinger, M. Paunovic, Modern Electroplating, fourth edition, John Wiley \& Sons, Inc., 2000.

26. R. Katırc1, A chrome coating from a trivalent chromium bath containing extremely low concentration of $\mathrm{Cr}^{3+}$ ions, Int. J. Surface Science and Engineering. 10 (2016) 73-85.

27. R. Katırc1, J. M. Walls, Systematic compositional changes and their influence on the structure of $\mathrm{Cu}_{2} \mathrm{ZnSnSe}_{4}$ coating, 2017 (Submitted)

28. Q. Cao, O. Gunawan, M. Copel, K.B. Reuter, S.J. Chey, V.R. Deline, et al., Defects in Cu (In, Ga) Se 2 chalcopyrite semiconductors: A comparative study of material properties, defect states, and photovoltaic performance, Adv. Energy Mater. 1 (2011) 845-853. 
29. M. Meng, L. Wan, P. Zou, S. Miao, J. Xu, Cu2ZnSnSe4 thin films prepared by selenization of one-step electrochemically deposited Cu-Zn-Sn-Se precursors, Appl. Surf. Sci. 273 (2013) 613616. 
Table 1. The composition of $\mathrm{Cu}, \mathrm{Zn}$ and Sn electrodeposition baths.

\begin{tabular}{lll}
\hline Cu bath & Zn bath & Sn bath \\
\hline $10 \mathrm{~g} / \mathrm{L} \mathrm{CuSO}_{4} .5 \mathrm{H}_{2} \mathrm{O}$ & $80 \mathrm{~g} / \mathrm{L} \mathrm{ZnCl}_{2}$ & $10 \mathrm{~g} / \mathrm{L} \mathrm{SnSO}_{4}$ \\
& $150 \mathrm{~g} / \mathrm{L} \mathrm{NH}_{4} \mathrm{OH}$ & $\begin{array}{l}100 \mathrm{~g} / \mathrm{L} \mathrm{K}_{4} \mathrm{P}_{2} \mathrm{O}_{7} \text { (potassium } \\
\text { pyrophosphate) }\end{array}$ \\
$\begin{array}{l}100 \mathrm{~g} / \mathrm{L} \mathrm{K}_{4} \mathrm{P}_{2} \mathrm{O}_{7} \text { (potassium } \\
\text { pyrophosphate) }\end{array}$ & & (2) \\
\hline
\end{tabular}


Table 2. Annealing pressures and times applied to the samples S1 to S6.

\begin{tabular}{lcccccc}
\hline & S1 & S2 & S3 & S4 & S5 & S6 \\
\hline Pressure (Torr) & 10 & 10 & 100 & 100 & 300 & 300 \\
Time (hour) & 1 & 2 & 1 & 2 & 1 & 2 \\
\hline
\end{tabular}




\section{Figure Captions}

Fig. 1. The position of measurements of the Raman spectra.

Fig. 2. Raman spectra of S1-S6 taken from the positions shown in Fig. 1.

Fig. 3. The peaks of XRD spectrum from sample S5.

Fig. 4. The concentration of Se (At \%) in the CZTSe coating at the annealing pressure of 10, 100 and 300 Torr.

Fig. 5. The surface morphology of the CZTSe samples obtained at different pressures and annealing times; a) 10 Torr 1 hour b) 10 Torr 2 hours c) 100 Torr 1 hour d) 100 Torr 2 hours e) 300 Torr 1 hour f) 300 Torr 2 hours.

Fig. 6. Surface morphology of S1.

Fig. 7. Micrographs of defects formed on the CZTSe surface.

Fig 8. The XRD peaks obtained from sample S1.

Fig. 9. Optical images of samples following an annealing process performed at a) 10 Torr and b) 300 Torr. 